\title{
Correlates of HIV and malaria co-infection in Southern India
}

\author{
Ajay R Bharti ${ }^{1 *}$, Shanmugam Saravanan², Vidya Madhavan², Davey M Smith ${ }^{1,3}$, Jabin Sharma², \\ Pachamuthu Balakrishnan ${ }^{2}$, Scott L Letendre ${ }^{1}$ and Nagalingeswaran Kumarasamy ${ }^{2}$
}

\begin{abstract}
Background: Malaria and HIV co-infection adversely impact the outcome of both diseases and previous studies have mostly focused on falciparum malaria. Plasmodium vivax contributes to almost half of the malaria cases in India, but the disease burden of HIV and P. vivax co-infection is unclear.

Methods: HIV-infected subjects ( $n=460$ ) were randomly selected from the 4,611 individuals seen at a Voluntary Counseling and Testing Center in Chennai, India between Jan 2 to Dec 31 2008. Malaria testing was performed on stored plasma samples by nested PCR using both genus-specific and species-specific primers and immunochromatography-based rapid diagnostic test for detecting antibodies against Plasmodium falciparum and $P$. vivax.

Results: Recent malaria co-infection, defined by the presence of antibodies, was detected in 9.8\% (45/460) participants. Plasmodium vivax accounted for majority of the infections (60\%) followed by P. falciparum (27\%) and mixed infections (13\%). Individuals with HIV and malaria co-infection were more likely to be men $(p=0.01)$. Between those with and without malaria, there was no difference in age $(p=0.14), C D 4+$ T-cell counts $(p=0.19)$ or proportion CD4+ T-cell below 200/mL ( $p=0.51)$.

Conclusions: Retrospective testing of stored plasma samples for malaria antibodies can facilitate identification of populations with high rates of co-infection, and in this southern India HIV-infected cohort there was a considerable burden of malaria co-infection, predominantly due to $P$. vivax. However, the rate of $P$. falciparum infection was more than 6-fold higher among HIV-infected individuals than what would be expected in the general population in the region. Interestingly, individuals co-infected with malaria and HIV were not more likely to be immunosuppressed than individuals with HIV infection alone.
\end{abstract}

Keywords: Plasmodium vivax, Plasmodium falciparum, Malaria, HIV, Co-infection, Malaria antibody, Retrospective test

\section{Background}

HIV, a sexually or parenterally transmitted viral infection, and malaria, a mosquito-borne parasitic disease, are two disparate and deadly diseases that are often brought together by overlapping geographic distributions. When HIV and malaria co-infection occur in the same individual, both diseases are adversely impacted. HIV-infected individuals are at increased risk of: acquiring malaria [1] developing severe malarial disease $[2,3]$, recrudescing malaria symptoms [4], and experiencing

\footnotetext{
* Correspondence: abharti@ucsd.edu

'University of California San Diego, San Diego, CA, USA

Full list of author information is available at the end of the article
}

treatment failure of malaria [5]. Additionally, acute malaria is associated with an increase in HIV viral load [6] and a steeper decline in CD4 cell count [7], and these viral load and CD4 count changes can take several weeks to recover after successful malaria therapy [6]. These interactions may facilitate spread of both diseases [8]. These observations have largely been made in the setting of HIV co-infection with Plasmodium falciparum in sub-Saharan Africa. Much less is known whether Plasmodium vivax has similar interactions with HIV. Therefore, this study was conducted to: i) determine the prevalence and risk factors of malaria co-infection in a cohort of HIV-infected individuals in southern India, a

\section{Biomed Central}


region with predominantly $P$. vivax malaria and ii) evaluate the strategy of using stored specimens for quick retrospective assessment of populations for co-infection burden.

\section{Methods}

\section{Study population}

The subjects were randomly selected (10\%) from the 4,611 HIV-1 positive individuals seen at the Voluntary Counseling and Testing center of Y. R. Gaitonde Center for AIDS Research and Education (YRGCARE) between Jan 2, 2008 and December 31, 2008. They were all newly diagnosed with HIV-1 infection and were not receiving antiretroviral therapy. The study was approved by the ethics boards of the University of California San Diego, YRGCARE, and the Indian Council of Medical Research. All volunteers provided written informed consent. Blood samples were processed immediately following collection and plasma stored in $-70^{\circ} \mathrm{C}$ freezer for a period ranging from 18 to 24 months before being evaluated in the current study.

\section{HIV and CD4+ T-cell count}

Blood (6 mL) was collected in EDTA tubes (catalog no. 367861, BD, USA) and plasma separated after centrifugation at 2,500 RPM for $12 \mathrm{~min}$. Tests for diagnosing HIV were either Determine HIV $1 / 2$ test (Abbott Laboratories), Signal HIV Rapid Test (Span Diagnostics Ltd., India), or First Response HIV 1-2.0 (PMC Medical Pvt. Ltd., India). CD4+ T-cell counts were determined by flow cytometric panLeukogating method (Beckman Coulter, USA).

\section{Malaria PCR}

DNA was extracted from $200 \mu \mathrm{L}$ of plasma sample using QIAamp DNA Blood Mini Kit (catalog no. 51106, Qiagen, USA). Nested PCR was done using both genus-specific and species-specific primers (Table 1) targeting the Plasmodium spp. 18S small subunit ribosomal RNA genes $[9,10]$. The first PCR was performed in a total volume of $20 \mu \mathrm{L}$ containing $3 \mu \mathrm{L}$ of extracted DNA, $17 \mu \mathrm{L}$ of iMaster Mix PCR Kit (catalog no. 25201, Intron Biotechnology, Korea), and forward and reverse primers $(0.2 \mu \mathrm{M})$. The nested species specific PCR was performed in a total volume of $20 \mu \mathrm{L}$ containing $1 \mu \mathrm{L}$ of PCR product. DNA, extracted from plasma of microscopy confirmed malaria positive ( $P$. falciparum and $P$. vivax) and malaria negative individuals, was used as positive and negative control, respectively. To confirm the presence of amplifiable human DNA, 20\% (90/460) samples were randomly selected and underwent PCR using primers for the human rRNA gene p53 [11].

\section{Malaria antibody testing}

An immunochromatography-based rapid diagnostic test kit, SD BIOLINE Malaria Pf/Pv Kit (Catalog No. 05FK30IIN-02, SD Bio Standard Diagnostics Pvt. Ltd., India), was used for detecting antibodies (IgG, IgM, IgA) against merozoite surface protein (MSP) of both $P$. falciparum and $P$. vivax. Each of the 460 plasma samples was tested individually for malaria antibodies. Blood smears were not available for examination by microscopy.

\section{Statistical analyses}

Student $t$-test was used for continuous variables and Chi-square test for categorical variables (IBM SPSS Statistics Version 19). Non-parametric test, Mann-Whitney $U$ test, was used where appropriate. One-way ANOVA was done to compare characteristics of the 3 malaria positive subgroups.

\section{Results}

Participant ages ranged from 21 to 68 years and $63 \%$ were male. Table 2 shows the demographic characteristics of the study cohort. Plasmodium antibodies were detected in plasma from 45 of the 460 participants (9.8\%). The majority of the infections were due to $P$. vivax (60\%) followed by P. falciparum (27\%) and mixed infections (13\%). Three-fourths of the co-infected individuals were in the 30-50 year range, but there was no difference in average age between those with and without malaria (38 vs. 40 years, $p=0.14$ ), median CD4+ T-cell counts (222 vs. $244 / \mu \mathrm{L}, p=0.19$ ) or proportion CD4+ Tcell below $200 / \mu \mathrm{L}(48 \%$ vs. $40 \%, p=0.51)$. The coinfected subjects, however, were more likely to be male ( $80 \%$ vs. $61 \%, p=0.01)$. Further analysis of the malaria positive groups ( $P$. vivax, $P$. falciparum, and mixed infections) did not show any significant difference in the

Table 1 Primers for nested PCR of Plasmodium 18S rRNA gene

\begin{tabular}{llll}
\hline Species & Primer & Sequence & Size of PCR product (bp) \\
\hline Plasmodium sp. & rPLU5 & CCTGTTGTGCCTTAAACTTC & 1,200 \\
& rPLU6 & TTAAAATTGTGCAGTTAAAACG & 205 \\
P. falciparum & rFAL1 & TTAAACTGGTTTGGAAAACCAAATATATT & 120 \\
& rFAL2 & ACACAATGAACTCAATCATGACTACCCGTC & \\
P. vivax & rVIV1 & CGCTTCTAGCTTAATCCACATAACTGATAC & \\
& rVIV2 & ACTTCCAAGCCGAGCAAAGAAAGTCCTTA & \\
\hline
\end{tabular}


Table 2 Demographic characteristics of the study cohort

\begin{tabular}{|c|c|c|c|}
\hline & \multirow{2}{*}{$\frac{\text { Malaria Neg }}{(\mathrm{N}=415)}$} & \multirow{2}{*}{$\begin{array}{c}\text { Malaria Pos } \\
(\mathrm{N}=45)\end{array}$} & \multirow[t]{2}{*}{$p$ value } \\
\hline & & & \\
\hline Mean age, y $( \pm S D)$ & $38 \pm 9$ & $40 \pm 9$ & 0.14 \\
\hline Gender (Number (\%) men) & $253(61 \%)$ & $36(80 \%)$ & 0.01 \\
\hline \multicolumn{4}{|l|}{ CD4+ cell count } \\
\hline Median, (IQR),/ $/ \mu \mathrm{L}$ & $222(89,403)$ & $244(140,571)$ & 0.19 \\
\hline Proportion below $200 / \mu \mathrm{L}$ & $48 \%(175 / 363)$ & $40 \%(15 / 38)$ & 0.51 \\
\hline \multicolumn{4}{|l|}{ Plasmodium species } \\
\hline P. vivax & & $27(60 \%)$ & \\
\hline P. falciparum & & $12(27 \%)$ & \\
\hline Mixed infections & & $6(13 \%)$ & \\
\hline
\end{tabular}

above characteristics (age, gender, median CD4+ and proportion below 200/ LL). Parasite DNA was not detected by PCR in any of the samples. Positive and negative controls were used with each batch of specimens processed and performed as expected. Amplifiable human DNA, tested using primers for the p53 gene, was found in $93 \%$ (84/90) of the randomly selected samples.

\section{Discussion}

In India, the potential for intersection of malaria and HIV epidemics is great but data on co-infections are sparse. Two studies, one conducted in Chennai and the other in Mumbai, have identified co-infected individuals in hospital-based settings $[12,13]$. However, this study is more representative of the community and is the first one to demonstrate a high $P$. vivax co-infection rate. The majority of the infections in this HIV-infected cohort were due to $P$. vivax (60\%), which is similar to that in the general population in the state of Tamil Nadu [14]. In contrast, compared to the general population [15], the co-infected cohort had a lower proportion of $P$. vivax (60\% vs. $96 \%$ ); higher proportion of $P$. falciparum (27\% vs. $4 \%$ ); and a considerable number of mixed infections (13\%). The higher prevalence of falciparum malaria in HIV-infected individuals has implications for clinical management. Incorrect identification of Plasmodium species can lead to inappropriate malaria treatment because chloroquine is still the first-line treatment for $P$. vivax [16], but would be ineffective for falciparum malaria due to high prevalence of chloroquine resistance [17].

There was a preponderance of men (80\%) with a mean age of $40 \pm 9$ years in the co-infected group, which mirrors the trend seen in the general population [14]. The high prevalence of malaria co-infection in men may be related to occupation and travel that puts them at an increased risk of being bitten by infected mosquitoes and needs to be investigated further. Interestingly, this study did not find an association between lower CD4+
T-cell count and malaria co-infection. This is in contrast to other studies where subclinical and symptomatic falciparum malaria was more common in HIV-infected compared with HIV-uninfected individuals and the risk increased with advancing immunosuppression $[1,18,19]$. Malaria in this cohort was mainly due to $P$. vivax and it is speculated that immunosuppression due to HIV may not increase the risk of vivax malaria co-infection, but more studies are needed to confirm this finding.

Malaria diagnosis was made by detection of malaria antibodies by the SD BIOLINE kit. Although, its sensitivity is much lower than microscopy or nested PCR and ranges from $47 \%$ to $69 \%[20,21]$, this method is well suited to detect malaria prevalence in low endemic areas $[22,23]$. The anti-MSP antibodies measured have very short half-lives (9.8 days) [24] that peak by day 7 and are cleared by day 28 [25]. In the absence of repeated infections in a region with unstable malaria transmission, this suggests that malaria infection in this co-infected group was recent, probably within a range of 1-4 weeks. Although data on symptoms or malaria treatment history was not collected, it is presumed that subjects were asymptomatic as they were seen in a HIV testing center and not a treatment clinic. No parasite DNA was detected using PCR-based methods. There could be several explanations for this. First, parasite DNA in stored plasma samples may have degraded. This is unlikely, as the authors have earlier shown that PCR is able to detect Plasmodium DNA in serum samples frozen up to $2 \frac{1}{2}$ years [26]. The current samples were more recent (less than 2 years old) and better preserved (stored at $-70^{\circ} \mathrm{C}$ ). Another point supporting specimen integrity is the presence of amplifiable human DNA in $93 \%$ of selected samples. Second, parasite DNA levels may be below the detection limit of PCR. Although, the sensitivity of the nested PCR method is high and ranges from $0.5-1$ parasite $/ \mu \mathrm{L}[27,28]$, plasma samples can have PCR yield up to 3-fold lower than whole blood [29]. Another reason for low parasitaemia levels is the high likelihood of subclinical infection among the participants. Realtime PCR may have a higher [30] or similar [21,27] sensitivity compared with nested PCR. Longitudinal data is lacking to confirm whether some individuals went on to develop symptomatic malaria or detectable parasite DNA. Further, tests were done only for P. falciparum and $P$. vivax, the two predominant Plasmodium species in the region and may have missed infections caused by other spp. like Plasmodium ovale and Plasmodium malariae although their contribution is unlikely given the antibody results.

\section{Conclusion}

Taken together, although malaria antibody test cannot be used to make a clinical diagnosis, it is a preferred 
method for retrospective malaria prevalence studies in regions with unstable malaria transmission, as in this study region.

\section{Competing interests}

The authors declare that they have no competing interests.

\section{Authors' contributions}

ARB, DMS, SLL, and NK conceived the study, SS, VM, JS, and PB implemented the study. ARB and DMS undertook data analyses, interpretation of results and drafted the manuscript. SLL and NK were involved in critical revision of the manuscript. All authors read and approved the final manuscript.

\section{Acknowledgements}

The authors disclose no conflict of interest related to the manuscript. This research was supported by a grant from the University of California, San Diego, Center for AIDS Research (CFAR), an NIH-funded programme (P30 Al036214), which is supported by the following NIH Institutes and Centers: NIAID, NCI, NIMH, NIDA, NICHD, NHLBI, NIA (PI: DMS; Co-PI: NK); ARB is supported by a K23 award from the National Institute of Mental Health (1K23MH085512-01A2).

\section{Author details}

${ }^{1}$ University of California San Diego, San Diego, CA, USA. ${ }^{2}$ YRGCARE Medical Centre, Chennai, India. ${ }^{3}$ Veterans Affairs Medical Center, San Diego, CA, USA.

Received: 19 June 2012 Accepted: 29 August 2012

Published: 3 September 2012

\section{References}

1. Patnaik P, Jere CS, Miller WC, Hoffman IF, Wirima J, Pendame R, Meshnick SR, Taylor TE, Molyneux ME, Kublin JG: Effects of HIV-1 serostatus, HIV-1 RNA concentration, and CD4 cell count on the incidence of malaria infection in a cohort of adults in rural Malawi. J Infect Dis 2005, 192:984-991.

2. Cohen C, Karstaedt A, Frean J, Thomas J, Govender N, Prentice E, Dini L, Galpin J, Crewe-Brown H: Increased prevalence of severe malaria in HIVinfected adults in South Africa. Clin Infect Dis 2005, 41:1631-1637.

3. Grimwade K, French N, Mbatha DD, Zungu DD, Dedicoat M, Gilks CF: HIV infection as a cofactor for severe falciparum malaria in adults living in a region of unstable malaria transmission in South Africa. AIDS 2004, 18:547-554.

4. Van Geertruyden JP, Mulenga M, Mwananyanda L, Chalwe V, Moerman F, Chilengi R, Kasongo W, Van Overmeir C, Dujardin JC, Colebunders R, Kestens L, D'Alessandro U: HIV-1 immune suppression and antimalarial treatment outcome in Zambian adults with uncomplicated malaria. $J$ Infect Dis 2006, 194:917-925.

5. Kamya MR, Gasasira AF, Yeka A, Bakyaita N, Nsobya SL, Francis D, Rosenthal PJ, Dorsey G, Havlir D: Effect of HIV-1 infection on antimalarial treatment outcomes in Uganda: a population-based study. J Infect Dis 2006, 193:9-15.

6. Kublin JG, Patnaik P, Jere CS, Miller WC, Hoffman IF, Chimbiya N, Pendame $R$, Taylor TE, Molyneux ME: Effect of plasmodium falciparum malaria on concentration of HIV-1-RNA in the blood of adults in rural Malawi: a prospective cohort study. Lancet 2005, 365:233-240.

7. Mermin J, Lule JR, Ekwaru JP: Association between malaria and CD4 cell count decline among persons with HIV. J Acquir Immune Defic Syndr 2006, 41:129-130.

8. Abu-Raddad L, Patnaik P, Kublin JG: Dual infection with HIV and malaria fuels the spread of both diseases in sub-Saharan Africa. Science 2006, 314:1603-1606.

9. Snounou G, Viriyakosol S, Jarra W, Thaithong S, Brown KN: Identification of the four human malaria parasite species in field samples by the polymerase chain reaction and detection of a high prevalence of mixed infections. Mol Biochem Parasitol 1993, 58:283-292.

10. Bharti AR, Letendre SL, Patra KP, Vinetz JM, Smith DM: Malaria diagnosis by a polymerase chain reaction-based assay using a pooling strategy. Am J Trop Med Hyg 2009, 81:754-757.

11. Shi SR, Datar R, Liu C, Wu L, Zhang Z, Cote RJ, Taylor CR: DNA extraction from archival formalin-fixed, paraffin-embedded tissues: heat-induced retrieval in alkaline solution. Histochem Cell Biol 2004, 122:211-218.
12. Shankarkumar U, Shankarkumar A, Ghosh K: HIV and malaria co-infection in Mumbai, Western India. J Vector Borne Dis 2011, 48:155-158.

13. Muthu M, Kumaar S: Study of malaria and HIV co-infection in Southern India. In 3rd international AIDS society conference on HIV pathogenesis and treatment: 2005. Rio de Janiero: International AIDS Society; 2005.

14. Kumar A, Valecha N, Jain T, Dash AP: Burden of malaria in India: retrospective and prospective view. Am J Trop Med Hyg 2007, 77(6 Suppl):69-78.

15. Malaria Situation in India: http://www.nvbdcp.gov.in/Doc/mal-situationJune12.pdf.

16. National drug policy on malaria: http://nvbdcp.gov.in/Doc/drug-policy-2010. pdf.

17. Valecha N, Joshi H, Eapen A, Ravinderan J, Kumar A, Prajapati SK, Ringwald $P$ : Therapeutic efficacy of chloroquine in plasmodium vivax from areas with different epidemiological patterns in India and their Pvdhfr gene mutation pattern. Trans R Soc Trop Med Hyg 2006, 100:831-837.

18. Whitworth J, Morgan D, Quigley M, Smith A, Mayanja B, Eotu H, Omoding N, Okongo M, Malamba S, Ojwiya A: Effect of HIV-1 and increasing immunosuppression on malaria parasitaemia and clinical episodes in adults in rural Uganda: a cohort study. Lancet 2000, 356:1051-1056.

19. French N, Nakiyingi J, Lugada E, Watera C, Whitworth JA, Gilks CF: Increasing rates of malarial fever with deteriorating immune status in HIV-1-infected Ugandan adults. AIDS 2001, 15:899-906.

20. Jeremiah ZA, Uko EK, Buseri Fl, Jeremiah TA: Field evaluation of SD bioline rapid malaria diagnostic test among asymptomatic malaria infected children in Port Harcourt, Nigeria. Res J Parasitol 2007, 2:39-44.

21. Lima GF, Levi JE, Geraldi MP, Sanchez MC, Segurado AA, Hristov AD, Inoue J, Costa-Nascimento Mde J, Di Santi SM: Malaria diagnosis from pooled blood samples: comparative analysis of real-time PCR, nested PCR and immunoassay as a platform for the molecular and serological diagnosis of malaria on a large-scale. Mem Inst Oswaldo Cruz 2011, 106:691-700.

22. Lee WJ, Kim HH, Hwang SM, Park MY, Kim NR, Cho SH, In TS, Kim JY, Sattabongkot J, Sohn Y, et al: Detection of an antibody against plasmodium vivax in residents of Gimpo-si, South Korea, using an indirect fluorescent antibody test. Malar J 2011, 10:19.

23. Duo-Quan W, Lin-Hua T, Zhen-Cheng G, Xiang Z, Man-Ni Y: Application of the indirect fluorescent antibody assay in the study of malaria infection in the Yangtze river three gorges reservoir, China. Malar J 2009, 8:199.

24. Kinyanjui SM, Conway DJ, Lanar DE, Marsh K: IgG antibody responses to plasmodium falciparum merozoite antigens in Kenyan children have a short half-life. Malar J 2007, 6:82.

25. Woodberry T, Minigo G, Piera KA, Hanley JC, de Silva HD, Salwati E, Kenangalem E, Tjitra E, Coppel RL, Price RN, Anstey NM, Plebanski M: Antibodies to plasmodium falciparum and plasmodium vivax merozoite surface protein 5 in Indonesia: species-specific and cross-reactive responses. J Infect Dis 2008, 198:134-142.

26. Bharti AR, Patra KP, Chuquiyauri R, Kosek M, Gilman RH, Llanos-Cuentas A, Vinetz JM: Polymerase chain reaction detection of plasmodium vivax and plasmodium falciparum DNA from stored serum samples: implications for retrospective diagnosis of malaria. Am J Trop Med Hyg 2007, 77:444-446.

27. Gama BE, Silva-Pires Fdo E, Lopes MN, Cardoso MA, Britto C, Torres KL, de Mendonca Lima L, de Souza JM, Daniel-Ribeiro CT, Ferreira-da-Cruz Mde F: Real-time PCR versus conventional PCR for malaria parasite detection in low-grade parasitemia. Exp Parasitol 2007, 116:427-432.

28. Snounou G, Viriyakosol S, Zhu XP, Jarra W, Pinheiro L, do Rosario VE, Thaithong S, Brown KN: High sensitivity of detection of human malaria parasites by the use of nested polymerase chain reaction. Mol Biochem Parasitol 1993, 61:315-320.

29. Lamikanra AA, Dobano C, Jimenez A, Nhabomba A, Tsang HP, Guinovart C, Manaca MN, Quinto L, Aguilar R, Cistero P, Alonso PL, Roberts DJ, Mayor A: A direct comparison of real time $P C R$ on plasma and blood to detect plasmodium falciparum infection in children. Malar J 2012, 11:201.

30. Genc A, Eroglu F, Koltas IS: Detection of plasmodium vivax by nested PCR and real-time PCR. Korean J Parasitol 2010, 48:99-103.

doi:10.1186/1475-2875-11-306

Cite this article as: Bharti et al:: Correlates of HIV and malaria coinfection in Southern India. Malaria Journal 2012 11:306. 